\title{
Relationship between lung function impairment and incidence or recurrence of cardiovascular events in a middle-aged cohort
}

\author{
A K Johnston, ${ }^{1}$ D M Mannino, ${ }^{1}$ G W Hagan, ${ }^{2}$ K J Davis, ${ }^{3}$ V A Kiri ${ }^{2}$
}

- Supplementary tables 1-3 are published online only at http:// thorax.bmi.com/content/vol63/ issue7

${ }^{1}$ Division of Pulmonary and Critical Care Medicine, University of Kentucky Medical Center, Lexington, Kentucky, USA; ${ }^{2}$ GlaxoSmithKline R\&D, Greenford, UK;

${ }^{3}$ GlaxoSmithKline Research and Development, Research Triangle Park, North Carolina, USA

Correspondence to: Dr D M Mannino, Division of Pulmonary and Critical Care Medicine, University of Kentucky Medical Center, 800 Rose Street, MN 614, Lexington, KY 40536; dmannino@uky.edu

Received 30 July 2007 Accepted 23 December 2007 Published Online First

1 February 2008

\section{ABSTRACT}

Introduction: Lung function impairment may be a risk factor for cardiovascular disease (CVD) events.

Objective: To determine the relationship between the severity of airflow obstruction based on modified Global Initiative on Obstructive Lung Disease (GOLD) criteria and the prevalence and incidence or recurrence of CVD in a cohort of US adults, aged 45-64 years, from 1987 to 2001.

Methods: We analysed data from 14681 adults using logistic regression to determine the cross sectional association between lung function impairment and prevalent CVD at baseline and Cox regression to examine the prospective association of lung function impairment at baseline with CVD over 15 years of follow-up. Models were adjusted for age, sex, race, smoking, comorbid hypertension and diabetes, cholesterol levels and fibrinogen level.

Results: At baseline, the crude prevalence of CVD was higher among subjects with GOLD 2 (OR 2.9, 95\% Cl 2.4 to 3.6) and GOLD 3 or 4 chronic obstructive pulmonary disease (COPD) (OR 3.0, 95\% Cl 2.0 to 4.5), compared with normal subjects. These relative risks were greatly reduced after adjusting for covariates (OR 1.4, 95\% Cl 1.1 to 1.8 for GOLD 2 and OR 1.3, 95\% Cl 0.8 to 2.1 for GOLD 3 or 4). Similarly, the association between COPD and risk of incident or recurrent CVD was much stronger in the unadjusted models (hazard ratio (HR) 2.4, 95\% Cl 2.1 to 2.7 for GOLD 2 and $2.9,95 \% \mathrm{Cl} 2.2$ to 3.9 for GOLD 3 or 4) than in the adjusted ones (HR $1.2,95 \% \mathrm{Cl} 1.03$ to 1.4 for GOLD 2 and 1.5, 95\% Cl 1.1 to 2.0 for GOLD 3 or 4). Conclusion: We observed a crude association between lung function impairment and prevalent and incident or recurrent CVD that was greatly reduced after adjusting for covariates, including age, sex, race, smoking, comorbid hypertension and diabetes, cholesterol levels and fibrinogen level. These data suggest that this association may be, in part, mediated through established CVD risk factors included in our adjusted models.

Ischaemic heart disease and cerebrovascular disease are currently the top two leading causes of death worldwide, responsible for more than one-fifth of all deaths, and are projected to remain so until 2020. ${ }^{12}$ Chronic obstructive pulmonary disease (COPD) is expected to be the third leading cause of worldwide mortality by 2020 and the fifth leading cause of disability adjusted life years lost. ${ }^{2}$ This triad of cardiac disease, stroke and COPD have an enormous economic, medical and social burden on adults in the USA. ${ }^{3-10}$ Processes that result in restriction on spirometry, which comprise interstitial lung diseases, diabetes mellitus, congestive heart failure and other causes of small lung volumes, also impart significant morbidity and mortality in the US. ${ }^{67}$ The role of systemic inflammation and systemic inflammatory markers such as $C$ reactive protein, fibrinogen and tumour necrosis factor $\alpha$ may be important in all of these disease processes. ${ }^{11-15}$

Cardiovascular mortality has been shown to be up to twofold higher in patients with COPD than in a matched population without COPD. ${ }^{5} 16$ Previous studies have linked lung function impairment with the risk of developing cardiovascular disease and stroke, even after adjusting for factors such as body mass index (BMI), physical activity, hypertension, diabetes and smoking status. ${ }^{517-23}$ However, lung function impairment in these studies has been classified by quartiles of forced expiratory volume in $1 \mathrm{~s}\left(\mathrm{FEV}_{1}\right)$ or mean $\mathrm{FEV}_{1}$ which are not routinely used clinically to assess the severity of impairment. ${ }^{18} 2021$

In 2001, the Global Initiative for Chronic Obstructive Lung Disease (GOLD) was formed to improve investigation and management of this complex disease and treatment strategies have been recommended based on GOLD staging. ${ }^{24}$ Our goal was to examine the prevalence, incidence and recurrence of cardiac events and stroke in the Atherosclerosis Risk in Communities (ARIC) cohort of adults, aged 45-64 years, and followed from 1987 to 2001 using a modification of the GOLD classification of lung function impairment.

\section{METHODS}

\section{Study population}

The ARIC study was initiated in 1987 as a longitudinal, population based study of the aetiology and clinical sequelae of atherosclerosis. Study protocols were approved for protection of human subjects. Participants were selected from the entire population by probability sampling from four US communities: Forsyth County, North Carolina; Minneapolis, Minnesota; Washington County, Maryland; and Jackson, Mississippi (where only African Americans were sampled). Specific details of the ARIC study are published elsewhere. ${ }^{25}$ Our analysis was limited to ARIC participants aged 45-64 years at baseline, who provided information on respiratory symptoms and diagnoses, cardiovascular events or stroke, and medical history, had lipid profiles available and who underwent adequate pulmonary function testing at the baseline examination. Only those participants for whom follow-up data were available were analysed $(n=14$ 681). 
Table 1 Definitions of prevalent, incident and recurrent cardiovascular disease and lung function impairment using a modification of the Global Initiative for Lung Disease (GOLD) criteria for chronic obstructive pulmonary disease

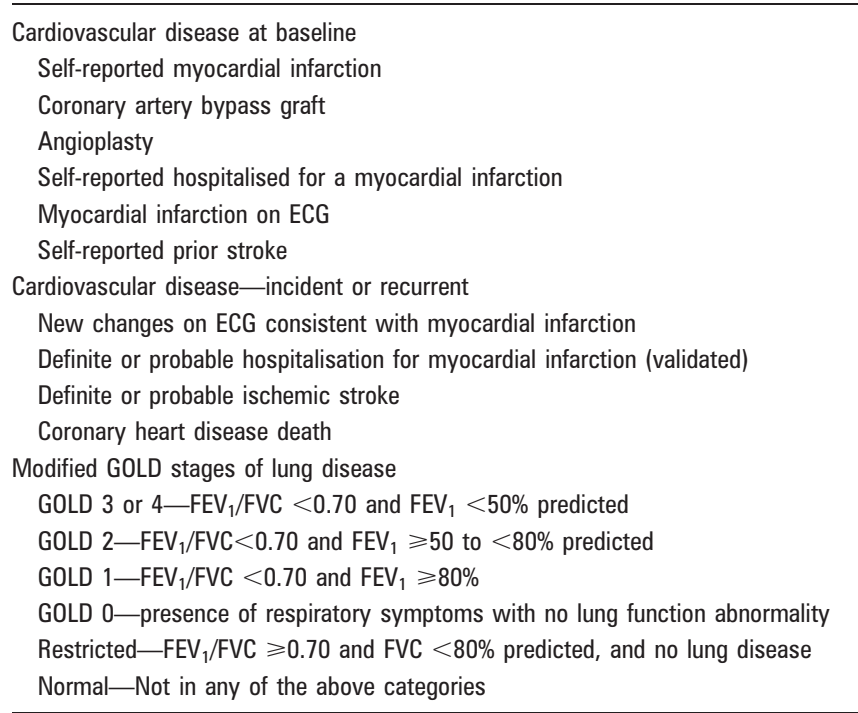

$\mathrm{FEV}_{1}$, forced expiratory volume in $1 \mathrm{~s}$; FVC, forced vital capacity.

\section{Pulmonary function data}

Spirometry was conducted using contemporary American Thoracic Society guidelines. ${ }^{26}{ }^{27}$ We developed sex and race specific internal prediction equations for $\mathrm{FEV}_{1}$ and $\mathrm{FVC}$ following standard methods previously described..$^{28}$ We defined a subject as having a respiratory symptom if they reported cough, phlegm, dyspnoea or wheeze.

A modification of the GOLD criteria was used to classify subjects according to their stage of $\mathrm{COPD}^{24}{ }^{29}$ : GOLD 3 or 4 $\left(\mathrm{FEV}_{1} /\right.$ forced vital capacity (FVC) $<0.70$ and $\mathrm{FEV} 1<50 \%$ predicted), GOLD $2\left(\mathrm{FEV}_{1} / \mathrm{FVC}<0.70\right.$ and $\mathrm{FEV}_{1} \geqslant 50$ to $<80 \%$ predicted), GOLD 1 ( $\mathrm{FEV}_{1} / \mathrm{FVC}<0.70$ and $\mathrm{FEV}_{1} \geqslant 80 \%$ predicted), restricted $\left(\mathrm{FEV}_{1} / \mathrm{FVC} \geqslant 70 \%\right.$ and $\mathrm{FVC}<80 \%$ predicted), GOLD 0 (presence of respiratory symptoms in the absence of any lung function abnormality) and no lung disease (table 1). Bronchodilator response was not evaluated so classification was based on "prebronchodilator" level. Only the baseline pulmonary function data were used to stratify participants, and they remained in these groups for interpretation of prevalent risk and incident or recurrent events.

\section{Ascertainment of baseline cardiovascular status and incident or recurrent events}

Cardiovascular disease (CVD) events included cardiac disease and stroke. CVD was considered present at baseline if the subject self-reported a myocardial infarction, coronary artery bypass graft, angioplasty, had been hospitalised for a myocardial infarction, had evidence on the ECG of a myocardial infarction or had a self-reported stroke at the baseline examination (table 1). ${ }^{25}$ Incident cardiac events were defined as a definite or probable hospitalised myocardial infarction, coronary heart disease death or myocardial infarction that was detected at follow-up by ECG changes (major $\mathrm{Q}$ wave or a minor $\mathrm{Q}$ wave with ischaemic ST-T changes or a myocardial infarction by computerised NOVACODE criteria, ${ }^{30}$ confirmed by side-to-side ECG comparison) who did not meet this criterion at baseline. ${ }^{31} 32$ CVD recurrence was defined as a definite or probable hospitalised myocardial infarction, coronary heart disease death or myocardial infarction that was detected at follow-up by ECG changes (major $\mathrm{Q}$ wave or a minor $\mathrm{Q}$ wave with ischaemic ST-T changes or a myocardial infarction by computerised NOVACODE criteria, confirmed by side-to-side ECG comparison) in those participants identified as having baseline cardiovascular disease. Stroke was defined according to published criteria related to the occurrence and duration of neurological signs and symptoms, the results of neuroimaging and diagnostic procedures, and treatments provided. ${ }^{10} 33$ The analysis was restricted to definite or probable ischaemic stroke only.

\section{Variable definitions}

Participants were classified as "former smokers" or "current smokers" based on positive responses to "Have you ever smoked cigarettes?" and "Do you now smoke cigarettes?", respectively. Pipe or cigar smokers were considered as "smokers" (ie, subjects who denied current cigarette smoking but reported current or former pipe or cigar smoking were considered current or former smokers, respectively). Never smokers were defined as persons who had not smoked more than 400 cigarettes in their lifetime and had never smoked pipes or cigars. Diabetes mellitus was defined as a baseline glucose level $\geqslant 126 \mathrm{mg} / \mathrm{dl}$ or use of a medication for diabetes or high blood sugar. Subjects were classified as having hypertension if they either reported a physician diagnosis of hypertension, were on treatment for hypertension or had evidence of hypertension at the examination (either a diastolic blood pressure $\geqslant 90 \mathrm{~mm} \mathrm{Hg}$ or a systolic blood pressure $\geqslant 140 \mathrm{~mm} \mathrm{Hg}$, based on three measurements). BMI was calculated as weight divided by height squared $\left(\mathrm{kg} / \mathrm{m}^{2}\right)$, measured at the baseline examination. Education level was categorised as less than high school, completion of high school or more than high school. High density lipoprotein cholesterol (HDL-C), low density lipoprotein cholesterol (LDL-C) and fibrinogen levels were measured in serum samples. ${ }^{34}$

\section{Analysis}

All analyses were conducted with SAS V.9.1 (SAS Institute, Cary, North Carolina, USA), SUDAAN V.9.0 (RTI, Research Triangle Park, North Carolina, USA) and SPSS V.10 (SPSS, Chicago, Illinois, USA).

Our primary outcome of interest was incidence or recurrence of cardiac events or stroke that occurred during the study period. Secondary outcomes were the relationship between prevalent CVD and lung function impairment at the baseline examination and the relationship between lung function impairment and CVD in the study population stratified by gender, age, race and smoking status. For CVD events, censoring occurred on the first CVD related hospitalisation or event, death or the date the person was last known to be alive. We developed Cox proportional hazards models using the procedure SURVIVAL in SUDAAN. Plots of the log-log survival curves for each covariate were produced to ensure that the proportional hazards assumptions were satisfied. Age, sex, race, smoking status, pack-years of smoking, BMI, education level, HDL-C, LDL-C, fibrinogen, diabetes mellitus and hypertension at baseline were included in the adjusted models. Analyses were also performed on subsets of subjects stratified by sex, race, smoking status and age category, and interactions were evaluated between these variables and our modified GOLD categories.

\section{RESULTS}

Our analysis included 14681 of the initial 15732 ARIC cohort participants. Excluded subjects did not differ significantly with regard to age, sex or smoking status ( $p>0.05$ for all) from 
Table 2 Demographic distribution of study participants, proportion with prevalent cardiovascular disease (CVD) at baseline, and results from univariate and multivariable logistic regression models

\begin{tabular}{|c|c|c|c|c|}
\hline & No $(\%)$ & $\begin{array}{l}\text { With prevalent } \\
\text { CVD at baseline } \\
(\%)^{*}\end{array}$ & $\begin{array}{l}\text { Univariate risk of } \\
\text { CVD at baseline } \\
\text { (OR }(95 \% \mathrm{CI}))\end{array}$ & $\begin{array}{l}\text { Multivariate risk of } \\
\text { CVD at baseline } \\
(\text { OR }(95 \% \text { CI })) \dagger\end{array}$ \\
\hline \multicolumn{5}{|l|}{ Age (y) } \\
\hline 45-49 & $3913(26.7)$ & $105(2.7)$ & 1.0 & 1.0 \\
\hline $50-54$ & $3806(25.9)$ & $172(4.5)$ & $1.7(1.3,2.2)$ & $1.4(1.1,1.8)$ \\
\hline $55-59$ & $3591(24.5)$ & $264(7.4)$ & $2.9(2.3,3.6)$ & $1.9(1.5,2.4)$ \\
\hline $60-64$ & $3026(22.9)$ & $345(10.2)$ & $4.1(3.3,5.2)$ & $2.3(1.8,3.0)$ \\
\hline \multicolumn{5}{|l|}{ Sex } \\
\hline Female & $8104(55.2)$ & $253(3.1)$ & 1.0 & 1.0 \\
\hline Male & $6577(44.8)$ & $633(9.6)$ & $3.3(2.9,3.8)$ & $2.3(1.9,2.7)$. \\
\hline \multicolumn{5}{|l|}{ Race } \\
\hline White & $10887(74.2)$ & $659(6.1)$ & 1.0 & 1.0 \\
\hline Black & $3794(25.8)$ & $227(6.0)$ & $1.0(0.9,1.2)$ & $1.0(0.8,1.2)$ \\
\hline \multicolumn{5}{|l|}{ Smoking status } \\
\hline Current smoker & $4170(28.4)$ & $291(7.0)$ & $2.3(1.9,2.7)$ & $0.9(0.6,1.4)$ \\
\hline Former smoker & 4751 (32.4) & $410(8.6)$ & $2.9(2.4,3.4)$ & $1.4(0.9,2.2)$ \\
\hline Never smoker & $5760(39.2)$ & $185(3.2)$ & 1.0 & 1.0 \\
\hline \multicolumn{5}{|l|}{ Pack-years } \\
\hline 60 or more & $711(4.8)$ & $126(17.7)$ & $6.1(4.8,7.7)$ & $2.5(1.6,4.2)$ \\
\hline $40-59$ & $1262(8.6)$ & 157 (12.4) & $4.0(3.2,5.0)$ & $2.1(1.3,3.3)$ \\
\hline $20-39$ & $2843(19.4)$ & $226(8.0)$ & $2.5(2.0,3.0)$ & $1.5(0.99,2.4)$ \\
\hline $1-19$ & $3434(23.4)$ & $145(4.2)$ & $1.3(1.01,1.6)$ & $0.9(0.6,1.5)$ \\
\hline Unknown & $240(1.6)$ & 21 (8.8) & $2.7(1.7,4.3)$ & $1.7(0.9,3.3)$ \\
\hline 0 & $6191(42.2)$ & $211(3.4)$ & 1.0 & 1.0 \\
\hline \multicolumn{5}{|l|}{ Diabetes mellitus } \\
\hline Yes & $1642(11.2)$ & $215(13.1)$ & $2.8(2.4,3.3)$ & $1.8(1.5,2.2)$ \\
\hline No & 13039 (88.8) & $671(5.2)$ & 1.0 & 1.0 \\
\hline \multicolumn{5}{|l|}{ Hypertension } \\
\hline Yes & $4992(34.0)$ & $485(9.7)$ & $2.5(2.2,2.9)$ & $1.9(1.7,2.3)$ \\
\hline No & $9689(66.0)$ & 401 (4.1) & 1.0 & 1.0 \\
\hline \multicolumn{5}{|l|}{ Body mass index } \\
\hline$<20$ & 477 (3.3) & $24(5.0)$ & $1.1(0.7,1.7)$ & $1.5(0.96,2.5)$ \\
\hline $20-24$ & $4446(30.3)$ & $209(4.7)$ & 1.0 & 1.0 \\
\hline $25-29$ & $5778(39.4)$ & $366(6.3)$ & $1.4(1.2,1.6)$ & $0.9(0.7,1.03)$ \\
\hline 30 and higher & $3980(27.1)$ & $287(7.2)$ & $1.6(1.3,1.9)$ & $0.8(0.7,1.01)$ \\
\hline \multicolumn{5}{|l|}{ Education (y) } \\
\hline$<12$ & $3423(23.3)$ & $321(9.4)$ & $2.1(1.8,2.5)$ & $1.5(1.2,1.8)$ \\
\hline 12 & $4764(32.5)$ & $260(5.5)$ & $1.2(0.99,1.4)$ & $1.2(0.96,1.4)$ \\
\hline$>12$ & 6494 (44.2) & $305(4.7)$ & 1.0 & 1.0 \\
\hline $\mathrm{HDL}-\mathrm{C}(\mathrm{mg} / \mathrm{dl}) \neq$ & & $52.0(0.1)$ & $0.67(0.63,0.71)$ & $0.81(0.76,0.87)$ \\
\hline LDL-C (mg/dl) & & $137.7(0.3)$ & $1.07(1.05,1.08)$ & $1.05(1.03,1.06)$ \\
\hline Fibrinogen $(\mathrm{mg} / \mathrm{dl}) \$$ & & $303.2(0.5)$ & $1.05(1.04,1.05)$ & $1.02(1.01,1.03)$ \\
\hline \multicolumn{5}{|l|}{ GOLD status* } \\
\hline GOLD 3 or 4 & $262(1.8)$ & $29(11.1)$ & $3.0(2.0,4.5)$ & $1.3(0.8,2.1)$ \\
\hline GOLD 2 & $1388(9.5)$ & $150(10.8)$ & $2.9(2.4,3.6)$ & $1.4(1.1,1.8)$ \\
\hline GOLD 1 & $1612(11.0)$ & $99(6.1)$ & $1.6(1.2,2.0)$ & $1.0(0.8,1.3)$ \\
\hline GOLD 0 & 2039 (13.9) & $132(6.5)$ & $1.7(1.4,2.0)$ & $1.4(1.1,1.8)$ \\
\hline Restricted & 1187 (8.1) & $148(12.5)$ & $3.4(2.8,4.2)$ & $2.3(1.9,2.9)$ \\
\hline Normal & $8193(55.8)$ & $328(4.0)$ & 1.0 & 1.0 \\
\hline Total & 14681 & $886(6.0)$ & & \\
\hline
\end{tabular}

From the Atherosclerosis Risk in Communities Study 1987-1989 and follow-up to 2001.

*Baseline CVD criteria and modified Global Initiative on Obstructive Lung Disease (GOLD) criteria, as defined in table 1.

$\uparrow$ Adjusted for age, sex, race, smoking status, pack-years of cigarettes, diabetes mellitus, body mass index, education level, hypertension, high density lipoprotein cholesterol (HDL-C), low density lipoprotein cholesterol (LDL-C), fibrinogen and GOLD status. tThird column displays mean value (SE). Risks are displayed per $10 \mathrm{mg} / \mathrm{dl}$ increase.

included subjects, but were more likely to be of black race $(p<0.01)$. The demographic distribution of the analysis cohort is included in table 2. Baseline 5 year age groups were evenly distributed from 45 to 64 years. The cohort was $55.2 \%$ female and $74.2 \%$ white. Diabetes was present in $11.2 \%$, hypertension in $34.0 \%$, overweight (BMI 25-29) in $39.4 \%$ and obesity (BMI $\geqslant 30$ ) in $27.1 \%$. Mean HDL-C level was 52.0 (SE 0.1) mg/dl, mean LDL-C was 137.7 (0.3) mg/dl and mean fibrinogen level was 303.3 (SE 0.5) mg/dl.

The baseline prevalence of CVD was $6.0 \%$ and higher among those with advanced age, male sex, presence of diabetes and hypertension, higher BMI and lower education level (table 2). The prevalence was also increased among current or former smokers and related to the number of pack-years. In the 
Table 3 Incident or recurrent cardiovascular events to 15 years of follow-up among subjects free of cardiovascular disease or stroke at baseline, those with cardiovascular disease or stroke at baseline and all subjects, stratified by GOLD stage*

\begin{tabular}{|c|c|c|c|c|c|}
\hline & $\mathbf{n}$ & $\begin{array}{l}\text { Incident or recurrent } \\
\text { cardiovascular } \\
\text { events per } 1000 \\
\text { person years* }\end{array}$ & $\begin{array}{l}\text { Deaths per } \\
1000 \\
\text { person } \\
\text { years }\end{array}$ & $\begin{array}{l}\text { Univariate risk of a } \\
\text { cardiovascular event } \\
\text { from Cox } \\
\text { proportional } \\
\text { hazards model } \\
\text { (hazard ratio } \\
(95 \% \mathrm{CI}))\end{array}$ & $\begin{array}{l}\text { Multivariate risk of } \\
\text { cardiovascular } \\
\text { event from Cox } \\
\text { proportional } \\
\text { hazards model } \\
\text { (hazard ratio } \\
(95 \% \text { Cl) }) \dagger\end{array}$ \\
\hline \multicolumn{6}{|c|}{ No cardiovascular disease at baseline } \\
\hline GOLD 3 or 4 & 233 & 16.8 & 46.4 & $2.2(1.6,4.0)$ & $2.0(1.03,3.9)$ \\
\hline GOLD 2 & 1238 & 13.5 & 18.0 & $1.7(1.3,2.3)$ & $1.3(0.96,1.9)$ \\
\hline GOLD 1 & 1513 & 8.4 & 9.7 & $1.4(0.9,2.0)$ & $1.3(0.9,1.8)$ \\
\hline GOLD 0 & 1907 & 9.0 & 8.7 & $1.3(0.96,1.9)$ & $1.2(0.9,1.7)$ \\
\hline Restricted & 1039 & 12.3 & 13.1 & $1.6(1.2,2.2)$ & $1.4(1.02,1.9)$ \\
\hline Normal & 7865 & 6.4 & 5.9 & 1.0 & 1.0 \\
\hline Total & 13795 & 8.1 & 8.8 & & \\
\hline \multicolumn{6}{|c|}{ Cardiovascular disease at baseline } \\
\hline GOLD 3 or 4 & 29 & 66.7 & 98.9 & $2.8(2.0,3.8)$ & $1.3(0.9,1.9)$ \\
\hline GOLD 2 & 150 & 54.4 & 39.1 & $2.1(1.8,2.5)$ & $1.2(0.98,1.4)$ \\
\hline GOLD 1 & 99 & 43.0 & 38.4 & $1.3(1.1,1.6)$ & $1.0(0.9,1.2)$ \\
\hline GOLD 0 & 132 & 41.9 & 37.2 & $1.4(1.2,1.7)$ & $1.1(0.9,1.3)$ \\
\hline Restricted & 148 & 50.9 & 39.2 & $2.0(1.6,2.3)$ & $1.2(0.98,1.4)$ \\
\hline Normal & 328 & 31.4 & 25.7 & 1.0 & 1.0 \\
\hline Total & 886 & 41.8 & 34.9 & & \\
\hline \multicolumn{6}{|l|}{ All subjects } \\
\hline GOLD 3 or 4 & 262 & 20.4 & 50.8 & $2.9(2.2,3.9)$ & $1.5(1.1,2.0)$ \\
\hline GOLD 2 & 1388 & 16.9 & 20.1 & $2.4(2.1,2.7)$ & $1.2(1.03,1.4)$ \\
\hline GOLD 1 & 1612 & 10.1 & 11.2 & $1.4(1.2,1.7)$ & $1.1(0.9,1.3)$ \\
\hline GOLD 0 & 2039 & 10.7 & 10.2 & $1.5(1.3,1.7)$ & $1.1(0.98,1.3)$ \\
\hline Restricted & 1187 & 16.1 & 16.0 & $2.3(2.0,2.6)$ & $1.2(1.1,1.5)$ \\
\hline Normal & 8193 & 7.2 & 6.6 & 1.0 & 1.0 \\
\hline Total & 14681 & 9.7 & 10.2 & & \\
\hline
\end{tabular}

unadjusted model, the prevalence of CVD was significantly higher in those with GOLD 2 (odds ratio (OR) 2.9, 95\% confidence interval (CI) 2.4 to 3.6) and GOLD 3 or 4 COPD (OR 3.0, 95\% CI 2.0 to 4.5$)$, compared with normal subjects. Adjustment for covariates decreased the relative risk for prevalent disease compared with the unadjusted model (OR 1.4, 95\% CI 1.1 to 1.8 for GOLD 2 and OR 1.3, 95\% CI 0.8 to 2.1 for GOLD 3 or 4 ). The highest overall multivariate association between baseline CVD and lung function impairment was observed for those classified as restricted (OR 2.3, 95\% CI 1.9 to 2.9).

The association between lung function impairment and risk of incident and recurrent CVD events over 15 years are shown in table 3. Subjects with baseline CVD were more likely to have a CVD event (41.8 events vs 8.1 events per 1000 person years) and to die (34.9 deaths vs 8.8 deaths per 1000 person years) than those without baseline CVD. Subjects with GOLD 2 (hazard ratio (HR) $2.4,95 \% \mathrm{CI} 2.1$ to 2.7 ) and GOLD 3 or 4 COPD (HR $2.9,95 \%$ CI 2.2 to 3.9 ) had the highest univariate risk of CVD events. This finding was decreased in the adjusted models (HR $1.2,95 \%$ CI 1.03 to 1.4 for GOLD 2 and $1.5,95 \%$ CI 1.1 to 2.0 for GOLD 3 or 4 COPD).

We did not find any significant interaction between the GOLD category and smoking status, age category, race or sex ( $p>0.10$ for each) for our primary outcome of time to CVD event. When the cohort was stratified by smoking status, the rate of CVD events and deaths was higher among current smokers (14.6 CVD events and 16.7 deaths per 1000 person years) than among former (10.0 CVD events and 9.8 deaths per 1000 person years) or never smokers (6.2 CVD events and 6.1 deaths per 1000 person years) (table 4). In the stratified analyses, the relation between lung function impairment, in the adjusted models, was weakest among the current smokers, but there was a large degree of overlap between all three smoking categories (table 4). The tables examining the relationship between CVD events and lung function impairment stratified by gender, age and race are available as an online supplement (supplementary tables 1-3). Men had twice the rate of CVD events than women (13.9 vs. 6.5 per 1000 person years), older subjects (age 55-64 years) had twice the rate of events than younger subjects (13.4 vs 6.5 per 1000 person years) and black patients had a slightly higher rate of events than white subjects (12.1 vs 8.9 per 1000 person years).

Figure 1 depicts the Kaplan-Meier curve of the relation between lung function impairment and incident or recurrent CVD, while fig 2 shows the fully adjusted Cox proportional hazards model curves.

\section{DISCUSSION}

In this analysis of a large, prospective, population based cohort, lung function impairment was associated with an increased risk 
Table 4 Incident or recurrent cardiovascular events* and death to 15 years of follow-up among never, former and current smokers stratified by GOLD stage*

\begin{tabular}{|c|c|c|c|c|c|}
\hline & $\mathbf{n}$ & $\begin{array}{l}\text { Incident or } \\
\text { recurrent } \\
\text { cardiovascular } \\
\text { events per } 1000 \\
\text { person years* }\end{array}$ & $\begin{array}{l}\text { Deaths per } \\
1000 \text { person } \\
\text { years }\end{array}$ & $\begin{array}{l}\text { Univariate risk of a } \\
\text { cardiovascular event } \\
\text { from Cox proportional } \\
\text { hazards model (hazard } \\
\text { ratio }(95 \% \text { CI)) }\end{array}$ & $\begin{array}{l}\text { Multivariate risk of } \\
\text { cardiovascular event } \\
\text { from Cox proportional } \\
\text { hazards model (hazard } \\
\text { ratio }(95 \% \mathrm{Cl})) \dagger\end{array}$ \\
\hline \multicolumn{6}{|l|}{ Never smokers } \\
\hline GOLD* 3 or 4 & 19 & 13.2 & 17.0 & $2.6(0.9,7.8)$ & $1.9(0.7,5.6)$ \\
\hline GOLD 2 & 185 & 9.4 & 9.5 & $1.8(1.2,2.9)$ & $1.5(0.96,2.3)$ \\
\hline GOLD 1 & 431 & 4.0 & 6.1 & $0.8(0.5,1.2)$ & $0.8(0.5,1.3)$ \\
\hline GOLD 0 & 761 & 8.0 & 6.9 & $1.5(1.2,2.0)$ & $1.2(0.9,1.6)$ \\
\hline Restricted & 469 & 12.2 & 12.8 & $2.4(1.8,3.1)$ & $1.5(1.1,1.9)$ \\
\hline Normal & 3895 & 5.3 & 4.9 & 1.0 & 1.0 \\
\hline Total & 5760 & 6.2 & 6.1 & & \\
\hline \multicolumn{6}{|l|}{ Former smokers } \\
\hline GOLD 3 or 4 & 88 & 24.5 & 49.7 & $3.3(2.1,5.2)$ & $2.3(1.5,3.6)$ \\
\hline GOLD 2 & 422 & 16.3 & 17.4 & $2.1(1.7,2.8)$ & $1.3(1.02,1.8)$ \\
\hline GOLD 1 & 564 & 10.2 & 9.2 & $1.3(1.03,1.7)$ & $1.1(0.9,1.5)$ \\
\hline GOLD 0 & 510 & 10.2 & 9.6 & $1.3(1.01,1.8)$ & $1.2(0.9,1.5)$ \\
\hline Restricted & 315 & 20.8 & 19.4 & $2.7(2.1,3.6)$ & $1.4(1.1,1.9)$ \\
\hline Normal & 2852 & 7.7 & 7.0 & 1.0 & 1.0 \\
\hline Total & 4751 & 10.0 & 9.8 & & \\
\hline \multicolumn{6}{|l|}{ Current smokers } \\
\hline GOLD 3 or 4 & 155 & 19.3 & 56.5 & $1.7(1.1,2.5)$ & $1.1(0.7,1.6)$ \\
\hline GOLD 2 & 781 & 19.2 & 24.3 & $1.7(1.3,2.0)$ & $1.1(0.9,1.4)$ \\
\hline GOLD 1 & 617 & 14.6 & 17.0 & $1.3(0.99,1.6)$ & $1.1(0.8,1.4)$ \\
\hline GOLD 0 & 768 & 13.9 & 14.2 & $1.2(0.9,1.5)$ & $1.0(0.8,1.3)$ \\
\hline Restricted & 403 & 17.3 & 17.0 & $1.5(1.1,1.9)$ & $0.9(0.7,1.2)$ \\
\hline Normal & 1446 & 11.7 & 10.7 & 1.0 & 1.0 \\
\hline Total & 4170 & 14.6 & 16.7 & & \\
\hline
\end{tabular}

of having or developing CVD in adults; the highest risks were observed among those with GOLD 2 (moderate) and GOLD 3 or 4 (severe/very severe) COPD. After adjusting for multiple covariates, including age, sex, race, smoking status, diabetes, hypertension, cholesterol levels and fibrinogen levels, the relation between lung function impairment and CVD was reduced, suggesting that some of this relation may be mediated through these other factors.

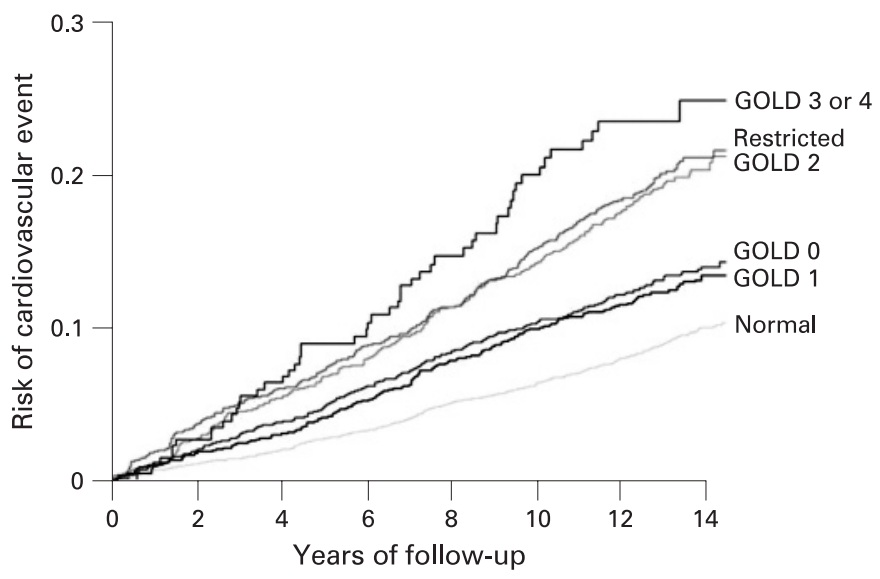

Figure 1 Kaplan-Meier curves of incident or recurrent cardiovascular events among all subjects by GOLD stage. From the Atherosclerosis Risk in Communities Study 1987-1989 and follow-up to 2001. Modified Global Initiative on Obstructive Lung Disease (GOLD); criteria and incident or recurrent cardiovascular disease criteria are defined as in table 1.
Previous research suggests that systemic inflammation present in COPD leads to the increased CVD risk, and that treatment aimed at decreasing inflammation in those with COPD may decrease the development of cardiovascular disease or reduce event recurrence. Vascular inflammation may also

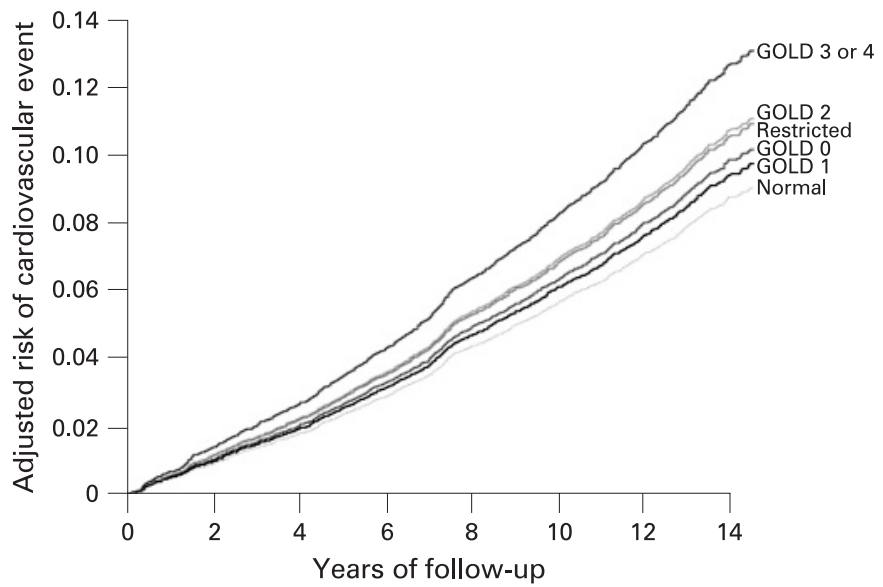

Figure 2 Multivariate risk of incident and recurrent cardiovascular events by GOLD stage. From the Atherosclerosis Risk in Communities Study 1987-1989 and follow-up to 2001. Modified Global Initiative on Obstructive Lung Disease (GOLD); criteria and incident or recurrent cardiovascular disease criteria are defined as in table 1. Adjusted for age, race, smoking status, diabetes mellitus, body mass index, education level, hypertension, high density lipoprotein of cholesterol, low density lipoprotein of cholesterol, fibrinogen, GOLD status and prevalent cardiovascular disease. 
contribute to impaired airway vascular smooth muscle relaxation in COPD. Treatment with agents that affect systemic inflammation or vascular disease such as corticosteroids, statins, angiotensin converting enzyme inhibitors or angiotensin receptor blockers have been shown to alter the prognosis of patients with COPD, ${ }^{35-39}$ and one retrospective meta-analysis has suggested a reduction in all-cause mortality in patients with COPD treated with inhaled corticosteroids. ${ }^{40}$ Our finding that the risk of CVD was greatly reduced in the models that adjusted for HDL-C, LDL-C, fibrinogen and comorbid disease suggests that part of the CVD risk seen in COPD is mediated by these other factors that may be responsive to intervention.

Although low grade chronic systemic inflammation likely contributes to the association between lung function impairment and CVD, factors such as the role of the lungs in the capture and elimination of external toxic agents may also be important. ${ }^{20}$

Previous research has shown a relationship between lung function impairment based on quartile of $\mathrm{FEV}_{1}$ per cent predicted or diagnosed COPD and incident cardiac disease or ischaemic stroke, with an increased risk primarily noted within population subsets, such as whites patients, ${ }^{18}$ women $^{20}{ }^{41}$ and younger populations. ${ }^{23}$ These analyses, however, were not able to make a distinction between those with mild, moderate or severe impairment in lung function or separate out those with restrictive impairment. Our study, however, used the clinically relevant GOLD staging to classify COPD, which does make this distinction.

An interesting finding in our study was the association between restriction on spirometry and CVD risk. As shown in table 2, restriction was a stronger risk factor for CVD than either GOLD 2 or GOLD 3 or 4 COPD, the risk for incident or recurrent $C V D$ in those with restriction was similar to that seen in GOLD 2 COPD. Neither the degree nor causes of restricted lung disease were examined in this analysis, but future studies may be undertaken to further investigate the relationship between CVD and restriction on spirometry.

Strengths of this study include the large cohort of patients, length of follow-up and well defined outcome events. Even though this was a very large sample, certain subgroups had small numbers. For example, the number of subjects with prevalent CVD was 150 for GOLD 2 and 29 for GOLD 3 or 4. Also, subjects were classified based on initial pulmonary function tests which may not have represented a true baseline, and the restriction category was categorised based on a decreased FVC with a normal $\mathrm{FEV}_{1} / \mathrm{FVC}$ ratio rather than the gold standard, total lung capacity measurements. The effect of lung function impairment on CVD outcomes was decreased in the fully adjusted models, suggesting that additional confounders that were not included in the analysis might explain these findings. Conversely, it is also possible that our models "over adjusted". For example, if the effect of lung function impairment on CVD is mediated through inflammation or comorbid disease, then adjusting for these factors might mask the true association between lung function impairment and CVD.

\section{CONCLUSION}

We observed an association between lung function impairment and risk of prevalent, and incident or recurrent, CVD in a large population based cohort. This association was reduced in models that adjusted for age, sex, race, smoking status, diabetes mellitus, hypertension, cholesterol levels and fibrinogen levels, suggesting that these effects may be mediated in part through these other factors. The implications of these findings are that clinicians should consider spirometry in their patients with
CVD or follow markers of systemic inflammation, such as C reactive protein, in COPD patients to help assess or manage their CVD risk. Future studies may be directed towards better identifying reasons for the linkage between lung function impairment and CVD risk and determining if interventions can improve outcomes.

Acknowledgements: The authors thank the staff and participants in the Atherosclerosis Risk in Communities Study for their important contributions. The ARIC Study is conducted and supported by the National Heart Lung and Blood Institute (NHLBI) in collaboration with the ARIC Investigators. This manuscript was not prepared in collaboration with investigators of the ARIC and does not necessarily reflect the opinions or views of the ARIC or the NHLBI.

Funding: Funded by a research grant from GlaxoSmithKline.

Competing interests: GW, KD, and VK are employees of GlaxoSmithKline (GSK). DM has received research funding from GSK, Pfizer and Novartis and is a consultant to GSK, Pfizer, AstraZeneca, Boehringer-Ingleheim, Dey and Sepracor. AJ has no competing interests.

Ethics approval: Ethics approval was obtained.

\section{REFERENCES}

1. Lopez AD, Mathers CD, Ezzati M, et al. Global and regional burden of disease and risk factors, 2001: systematic analysis of population health data. Lancet 2006;367:1747-57.

2. Murray CJ, Lopez AD. Alternative projections of mortality and disability by cause 1990-2020: Global Burden of Disease Study. Lancet 1997;349:1498-504.

3. Burrows B. Predictors of loss of lung function and mortality in obstructive lung diseases. Eur Respir Rev 1991;1:340-5.

4. Gibbons L, Shapiro SH, Martin JG, et al. Predictors of mortality in severe chronic obstructive pulmonary-disease (COPD). Am J Epidemiol 1990;132:821.

5. Huiart L, Ernst P, Suissa S. Cardiovascular morbidity and mortality in COPD. Chest 2005:128:2640-6.

6. Mannino DM, Doherty DE, Buist AS. Global Initiative on Obstructive Lung Disease (GOLD) classification of lung disease and mortality: findings from the Atherosclerosis Risk in Communities (ARIC) study. Respir Med 2006;100:115-22.

7. Mannino DM, Holguin F, Pavlin BI, et al. Risk factors for prevalence of and mortality related to restriction on spirometry: findings from the First National Health and Nutrition Examination Survey and follow-up. Int J Tuberc Lung Dis 2005;9:613-21.

8. Ryan G, Knuiman MW, Divitini ML, et al. Decline in lung function and mortality: the Busselton Health Study. J Epidemiol Community Health 1999;53:230-4.

9. Gulsvik A. The global burden and impact of chronic obstructive pulmonary disease worldwide. Monaldi Arch Chest Dis 2001;56:261-4

10. Rosamond WD, Folsom AR, Chambless LE, et al. Stroke incidence and survival among middle-aged adults: 9-year follow-up of the Atherosclerosis Risk in Communities (ARIC) cohort. Stroke 1999;30:736-43.

11. Andreas S, Anker SD, Scanlon PD, et al. Neurohumoral activation as a link to systemic manifestations of chronic lung disease. Chest 2005;128:3618-24.

12. Gan W0, Man SF, Senthilselvan A, et al. Association between chronic obstructive pulmonary disease and systemic inflammation: a systematic review and a metaanalysis. Thorax 2004;59:574-80.

13. Mannino DM, Ford ES, Redd SC. Obstructive and restrictive lung disease and markers of inflammation: data from the Third National Health and Nutrition Examination. Am J Med 2003;114:758-62.

14. Sevenoaks MJ, Stockley RA. Chronic obstructive pulmonary disease, inflammation and co-morbidity-a common inflammatory phenotype? Respir Res 2006; 7:70.

15. Sin DD, Man SF. Why are patients with chronic obstructive pulmonary disease at increased risk of cardiovascular diseases? The potential role of systemic inflammation in chronic obstructive pulmonary disease. Circulation 2003;107:1514-19.

16. Curkendall SM, DeLuise C, Jones JK, et al. Cardiovascular disease in patients with chronic obstructive pulmonary disease, Saskatchewan Canada cardiovascular disease in COPD patients. Ann Epidemiol 2006;16:63-70.

17. Howard G, Wagenknecht LE, Burke GL, et al. Cigarette smoking and progression of atherosclerosis: The Atherosclerosis Risk in Communities (ARIC) Study. JAMA 1998;279:119-24.

18. Hozawa A, Billings $J L$, Shahar $E$, et al. Lung function and ischemic stroke incidence: the Atherosclerosis Risk in Communities study. Chest 2006;130:1642-9.

19. Pistelli R, Lange P, Miller DL. Determinants of prognosis of COPD in the elderly: mucus hypersecretion, infections, cardiovascular comorbidity. Eur Respir J Supp/ 2003;40:10s-14.

20. Schroeder EB, Welch VL, Couper D, et al. Lung function and incident coronary heart disease: the Atherosclerosis Risk in Communities Study. Am J Epidemiol 2003; 158:1171-81.

21. Schroeder EB, Welch VL, Evans GW, et al. Impaired lung function and subclinical atherosclerosis. The ARIC Study. Atherosclerosis 2005;180:367-73.

22. Zureik M, Kauffmann F, Touboul PJ, et al. Association between peak expiratory flow and the development of carotid atherosclerotic plaques. Arch Intern Med 2001:161:1669-76. 
23. Sidney S, Sorel M, Quesenberry CP Jr, et al. COPD and incident cardiovascular disease hospitalizations and mortality: Kaiser Permanente Medical Care Program. Chest 2005;128:2068-75.

24. Pauwels RA, Buist AS, Calverley PM, et al. Global Strategy for the Diagnosis, Management, and Prevention of Chronic Obstructive Pulmonary Disease. NHLBI/WHO Global Initiative for Chronic Obstructive Lung Disease (GOLD) workshop summary. Am J Respir Crit Care Med 2001;163:1256-76.

25. The Atherosclerosis Risk in Communities (ARIC) Study: design and objectives. The ARIC investigators. Am J Epidemiol 1989;129:687-702.

26. American Thoracic Society. Standardization of Spirometry, 1994 Update. Am J Respir Crit Care Med 1995;152:1107-36.

27. American Thoracic Society. Standardization of Spirometry. Am Rev Respir Dis 1979;119:831-8

28. Ferdinands JM, Mannino DM, Gwinn ML, et al. ADRB2 Arg16Gly polymorphism, lung function, and mortality: results from the Atherosclerosis Risk in Communities study. PLoS One 2007;2:e289.

29. Celli BR, MacNee W. Standards for the diagnosis and treatment of patients with COPD: a summary of the ATS/ERS position paper. Eur Respir J 2004;23:932-46.

30. Rautaharju PM, Calhoun HP, Chaitman BR. NOVACODE serial ECG classification system for clinical trials and epidemiologic studies. J Electrocardiol 1992;24(Suppl):179-87.

31. Kors JA, Crow RS, Hannan PJ, et al. Comparison of computer-assigned Minnesota Codes with the visual standard method for new coronary heart disease events. Am J Epidemio/ 2000;151:790-7.

32. Machado DB, Crow RS, Boland LL, et al. Electrocardiographic findings and incident coronary heart disease among participants in the Atherosclerosis Risk in Communities (ARIC) study. Am J Cardiol 2006;97:1176-81.
33. Rathore SS, Hinn AR, Cooper LS, et al. Characterization of incident stroke signs and symptoms: findings from the atherosclerosis risk in communities study. Stroke 2002;33:2718-21

34. Howard G, Manolio TA, Burke GL, et al. Does the association of risk factors and atherosclerosis change with age? An analysis of the combined ARIC and CHS cohorts. The Atherosclerosis Risk in Communities (ARIC) and Cardiovascular Health Study (CHS) investigators. Stroke 1997:28:1693-701.

35. Huiart L, Ernst P, Ranouil X, et al. Low-dose inhaled corticosteroids and the risk of acute myocardial infarction in COPD. Eur Respir $J$ 2005;25:634-9.

36. Huiart L, Ernst P, Ranouil $X$, et al. Oral corticosteroid use and the risk of acute myocardial infarction in chronic obstructive pulmonary disease. Can Respir $J$ 2006;13:134-8.

37. Mancini GB, Etminan M, Zhang B, et al. Reduction of morbidity and mortality by statins, angiotensin-converting enzyme inhibitors, and angiotensin receptor blockers in patients with chronic obstructive pulmonary disease. J Am Coll Cardiol 2006; 47:2554-60.

38. Albert MA, Danielson E, Rifai N, et al. Effect of statin therapy on C-reactive protein levels: the pravastatin inflammation/CRP evaluation (PRINCE): a randomized trial and cohort study. JAMA 2001;286:64-70

39. Calverley $\mathbf{P}$, Pauwels R, Vestbo J, et al. Combined salmeterol and fluticasone in the treatment of chronic obstructive pulmonary disease: a randomised controlled trial. Lancet 2003;361:449-56.

40. Sin DD, Wu L, Anderson JA, et al. Inhaled corticosteroids and mortality in chronic obstructive pulmonary disease. Thorax 2005;60:992-7.

41. Onufrak S, Abramson J, Vaccarino V. Adult-onset asthma is associated with increased carotid atherosclerosis among women in the atherosclerosis risk in communities (ARIC) study. Atherosclerosis 2007;195:129-37.

\section{Keep up to date: sign up for our alerting services}

Find out automatically when an article is published on a specific topic or by a particular author. We can also alert you when an article is cited or if an eLetter or correction is published. You can also choose to be alerted when a new issue is published online [and when we post articles Online First]. Check out the New Content Alerts and Citation tracker from the Online tools section on the home page. 